\title{
Valuation of Ecosystem Services and Environmental Damages: An Imperative Tool for Decision Making and Sustainability
}

\author{
Hemant Bherwani ${ }^{1,2 \star}$, Moorthy Nair ${ }^{1}$, Atya Kapley ${ }^{1,2}$, Rakesh Kumar ${ }^{1,2}$
}

${ }^{1}$ CSIR-National Environmental Engineering Research Institute (NEERI), Nagpur, Maharashtra, INDIA

${ }^{2}$ Academy of Scientific and Innovative Research (AcSIR), Ghaziabad, Uttar Pradesh, INDIA

*Corresponding Author: h.bherwani@neeri.res.in

Citation: Bherwani, H., Nair, M., Kapley, A. and Kumar, R. (2020). Valuation of Ecosystem Services and Environmental Damages: An Imperative Tool for Decision Making and Sustainability. European Journal of Sustainable Development Research, 4(4), em0133. https://doi.org/10.29333/ejosdr/8321

\section{ARTICLE INFO}

Received: 30 Dec. 2019

Accepted: 27 May 2020

\begin{abstract}
Economics being a major field in management has paved its way into environment to tackle the issues concerned with environmental/ecosystem services degradation and is acting as an aspect of human wellbeing and sustainability. Environmental degradation due to pollution is very well known and is measured thoroughly throughout the world. However, the end point impacts are seldom measured and not reported. There are very few responsible companies in the world who are aware about this fact and are reporting these externalities, or the third-party impacts, of their businesses. Various facets of ecosystem services on the other hand are known and have various measurement frameworks as well. The current paper discusses both the aspects i.e. ecosystem services and environmental externalities with respect to assessment techniques and highlights the way in which these fields have developed over the years along with their current methods and trends. The paper will help researchers and policy makers, working in this field, by making them aware about various means by which these estimations can be done so that the gap between environmental degradation and sustainability can be bridged.
\end{abstract}

Keywords: Ecosystem services, Environmental economics, Environmental damage cost assessment, Millennium Ecosystem Assessment (MEA), The Economics of Ecosystem and Biodiversity (TEEB), Ecosystem valuation tool, Payment Ecosystem Services (PES), Environmental degradation, Natural capital

\section{INTRODUCTION}

Environmental economics and ecological economics are relatively new terms in the field of economics. The core fields of environment and ecology are still buying-in to the concept of economics in these fields (Ropke, 2004). Although the term of environmental economics was coined in the 1960s but the literature which led to the development of this field is relatively old and the roots of it can be traced back in the eighteenth century (Agudelo et al., 2019). Indeed, the true development of the fields has happened in the last 3 to 4 decades with the contributions of many well-known economists and environmentalists (Sandmo, 2015).

Environmental economics developed as a field, as it is known today, because of raising awareness amongst the governments, institutions and wider general public about the intensification of pollution and it's harmful effects. Generally, for a country, economic growth is welfare gains due to higher consumption levels and thereby they generally plan to invest in latest technologies (Pece et al., 2015). Having said that, it is of no coincidence that the fastest-growing countries are the highest emitters/polluters (Aye and Edoja, 2017). If the pollution is bonded with this economic growth, adopting mitigative measures may result in slowdown of the growth. Countries chasing lucrative deals may limit themselves due to the mitigative measure adopted to curb pollution, overcoming this limitation causes local damages such as effect on productivity (Graf and Neidell, 2012; Hanna and Oliva, 2015), human health (Cohen et al., 2017) and trade-offs. To recognize the working principle and intensity with respect to the exchange between environmental quality and economical flourishment has turned out to be a challenging scenario in the current world (Kelsey, 2017). Moreover, in general, people started realizing that taking care of nature is important as we thrive upon it. Further, economists have started understanding that it is essential to incorporate environment and natural resources in some or other form into the current system of economic growth assessment. In order to ensure the sustainability of scarce resources, a wider lookout is being developed considering the dependability of human within the environment (Mori et al., 2012). This had led to panic regarding the depletion of resources and extinction due to human actions that ultimately impacts the human wellbeing (De Groot, 1987). This concern also triggered among the business analysts as the survival of their current businesses depends upon the environment and natural resources and hence the term natural capital originated performing the functions of life support 


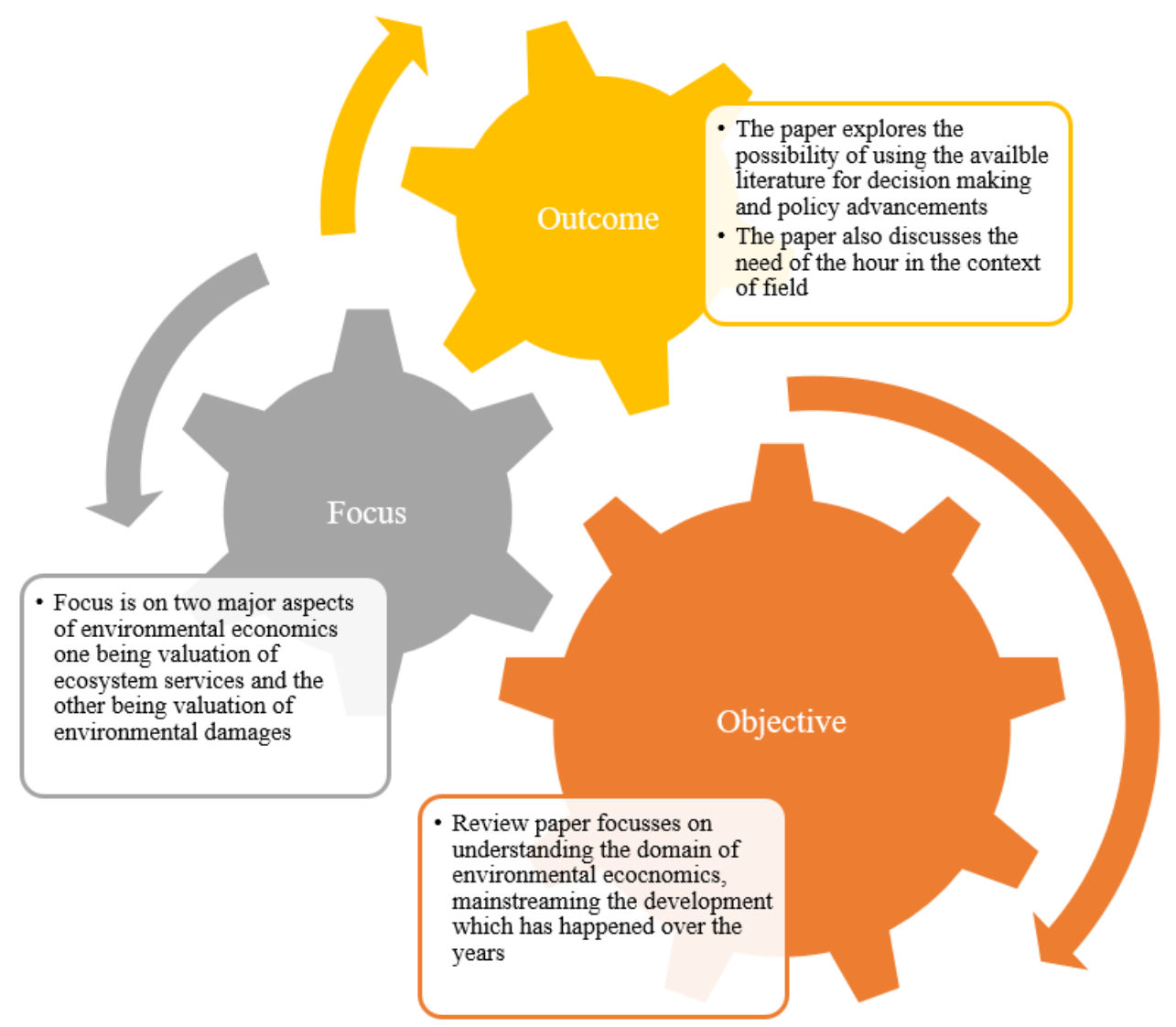

Figure 1. Brief overview about the review in the context of valuation of environmental parameters

which in turn cannot be performed by other manmade capitals such as physical capital or intellectual capital. "Natural capital constitutes of world's stocks of natural assets which include geology, soil, air, water, and all living things." (De Groot et al., 2003).

Given that it is understood by the world and the experts in the field of environment, ecology and economics, that it is necessary to mainstream the function of "natural capital" in the current mechanism of evaluation of profits, losses and GDP calculations, the current research has been done to understand what all has happened in this field of environmental economics and what is needed for the future. Furthermore, to achieve long term growth in every aspect, sustainable development is very important and hence it became a notion in modern economic policy as well. Sustainability in terms of economics is to improve the wellbeing of humans with time on a sustained basis (Lorek et al., 2014). "Sustainable development is a development where the current generation retains the natural resources to meet the demand of future generation without comprising the current needs" (Pearce, 2002). However, there exists several studies carried out previously on services availed from various ecosystem (Amato et al., 2016; Baveye et al., 2016; Mengist and Soromessa, 2019; Sanchez et al., 2019; Schirpke et al., 2019; Xie et al., 2020) but is limited when it comes to assessing the potential damages (Bherwani et al., 2019; European Commission, 2000; Sancho et al., 2010). Figure 1 gives an idea about the context of the paper.

\section{ESTABLISHMENT OF FIELD OF NATURAL CAPITAL}

There are two aspects to natural capital and related externalities (third party impacts), one being the damage of natural environment because of waste generation and pollutants discharge from the current business practices and the other aspect of loss of ecosystem services and the biodiversity on land water and air and the resources therein (Brokerhoff et al., 2017). The aspects of pollution have been fairly clear from the very beginning but lacked in expressing its value in monetary terms. Validating ecosystem services in terms of money is an efficient tool that allows policymakers to utilize the funds by identifying the area where protection and restoration are important (Crossman and Bryan, 2009, Crossman et al., 2011). It is the inherent link between the natural resources and biodiversity and the business which is not understood so easily (Winn et al., 2013).

The aspect of environmental economics deals with the following points (TEEB Interim Report, 2008; TEEB Synthesis, 2010; TEEB National and International Policy Making, 2011; TEEB business and Enterprise, 2012)

- Is situation responsible for environmental problems and degradation?

- Assessing the potential damage cost to environment

- Mitigative measures to minimize environmental-related problems and degradation.

The aspect of biodiversity and ecosystem has gained importance and has grown over the years. Biodiversity refers generally to variability within the living environment. It encompasses the variability of plants and animal species, the variability of the 
Table 1. Categories of the services provided by ecosystem and biodiversity

\begin{tabular}{|c|c|c|}
\hline Service Providers & Significance of service providers on human well being & Examples \\
\hline Provisioning & Provides direct end product from Ecosystem for daily livelihood & $\begin{array}{l}\text { Nourishment sources, } \\
\text { Energy sources, } \\
\text { Aesthetic sources, } \\
\text { Aqua sources etc }\end{array}$ \\
\hline Regulating & $\begin{array}{l}\text { This service provider regulates the negative impacts of the } \\
\text { ecosystem on human wellbeing }\end{array}$ & $\begin{array}{l}\text { Maintain air quality, } \\
\text { Regulate climate change, } \\
\text { Prevent soil erosion, flood, and storm. } \\
\text { Control sickness-related factors in human etc }\end{array}$ \\
\hline Supporting & $\begin{array}{l}\text { Humans are indirectly benefited for over a longer time as these } \\
\text { benefits remaining service providers of the ecosystem (Provisioning, } \\
\text { Regulating \& Culture services). }\end{array}$ & Water cycle, Nutrient cycle, etc \\
\hline Cultural & Nonmaterial benefits people obtain from ecosystems & $\begin{array}{l}\text { Spiritual enrichment, cognitive development, } \\
\text { reflection, recreation, and aesthetic experiences }\end{array}$ \\
\hline
\end{tabular}

genetic makeup of those species and the variability of the ecosystem in which the species interact (REF). Services from the ecosystem through which humans are benefited either directly or indirectly are called ecosystem services. Biodiversity \& Ecosystem which holds numerous functions on earth is in danger due to overexploitation/modifications vis a vis climate change (Roe., 2019). The realization of the same has led to certain initiatives by the United Nations (MEA, 2005) on Ecosystem and human well-being reported some major findings regarding the management of ecosystems that resulted in significant degradation a) overexploitation b) irreversible loss incurred with ecosystem c) Policy \& Regulations set by authorities. The study also reported that degradation of over $60 \%$ was due to overexploitation for human wellbeing. The changes made in the ecosystem have surely fetched an increasing trend in economic development with subsequent degradation of the ecosystem with irreversible changes aggravating the poverty among poor. The Millennium Ecosystem Assessment was initiated during $21^{\text {st }}$ century to evaluate the changes in ecosystem due to human wellbeing and corresponding measures to be implemented to enhance the chance of sustainability that contribute wellbeing of human. According to the Millennium Ecosystem Assessment (MEA), Ecosystem service providers are split into four categories as shown in Table 1 (Alcamo et al., 2003). MEA has listed some of the major findings associated with our management of the world's ecosystems which are significantly harming the people (MEA, 2005).

a) Overexploitation of the ecosystem has resulted in its degradation. This degradation can sustainably affect future generations.

b) Changes in the ecosystem have improved well-being and economic statics but substantially have resulted in an irreversible loss in the ecosystem.

c) Degradation of the ecosystem can be reversed without comprising of their services by bringing changes in regulations set by authorities.

d) Decline in ecosystem service has majorly targeted poor causing social conflict and poverty.

e) If overexploitation is continued at the same pace, no improvisation in terms of health, hunger eradication and sustainability is likely to be achieved.

Ecosystem services are basics for various researchers who validates the human dependence on environment which further triggered policymakers like TEEB (The Economics of Ecosystem and Biodiversity) demanding a validation on loss in ecosystem service thereby affecting human welfare (Lele and Srinivasan, 2013). MEA did not consider the concept of economics of ecosystem change. Hence a new framework (Balmford et al., 2008) was proposed during TEEB 2008 for a clear study related to the ecological and economic aspect of research for validating loss and degradation of biodiversity and ecosystem respectively. This was done after the MEA in 2001-2005. Major findings as per TEEB as follows (TEEB synthesis, 2010).

a) Negligence towards natural capital to improve economic growth has resulted in the loss of biodiversity and ecosystem. The loss will tend to be accelerating as a serious issue if the degradation trend continues as usual.

b) Assigning monetary values for ecosystem services was complex and substantially the evaluation of ecosystem services remained poorly understood. Hence Economics parts of the services need to gain more attention when it comes to the valuation of biodiversity and ecosystem.

c) Ecosystem has the ability to provide service irrespective of environmental conditions. This natural cover needs to be considered in the overall validation of ecosystem economics.

d) Standard national account has failed to include natural capital stocks in the list when it comes to measurement of economic performance and wealth. This system must be upgraded to include the changes associated with ecosystem services and natural capital stocks.

e) Managing sustainable natural capital can be a major objective in poverty eradication.

f) To encourage various sectors in providing ecosystem services principles of beneficiary pays can be adopted to support payment ecosystem, tax breaks, and other financial transfers.

g) A compressive structure of fairly represented and supervised system of regional and national protected areas should be tracked to conserve the biodiversity and ecology. 
h) Avoiding degradation of the ecosystem and human restoration of ecological units, both are considered a feasible option in achieving various benefits that support human welfare such as climate regulation, treated water quality, urbanization, etc.

i) Elimination of evaluation of ecosystem services has resulted in substantial degradation of natural assets. The complete value of ecosystem services helps in creating awareness in sustainably managing the biodiversity.

There are many resources available in nature that are useful to many human beings and plant and animal biodiversity but they are usually destroyed because their importance is neither evident nor have been valued and presented in the current framework of valuation of resources. The fact that most of the businesses are for-profit, they tend to ignore the fact that natural resources have intangible benefits as well that may not have been evaluated (Small et al., 2017). Many of the poor people utilize natural resources for their livelihood which may be destroyed as a result of polluted ecosystems or hindrance to a big for-profit business cause. This resulted in a new concept, during the development of TEEB, called "GDP of the poor" concept by TEEB in 2010, which estimates the above values for countries like India, Indonesia, and Brazil where native people thrive upon the natural ecosystem services. These microtransactions between people and nature are invisible to the current modus operandi (Gillies, 2010). The costs and prices are calculated only to a level of the human requirement but the overall benefits of biodiversity and ecosystem services are not considered in our day to day economic activities. In this sense, these values are invisible to the current economic system. Within this context, trailing sections explore the developments in the realm of environmental damage cost assessment and ecosystem services valuation (ESV). Moreover, as stated, study signifies the overall development in the field of ecosystem services and potential damage cost valuation methodology benefiting both researchers and policymakers in decision making as concern towards a sustainable environment.

\section{VALUATION OF ECOSYSTEM SERVICES}

The valuation of Ecosystem services started with a policy stating that biodiversity and associated services are no more inexhaustible and complimentary. Their need for human welfare, monetary losses are a result of degradation need to be validated (Blignaut and Moolman, 2006; Carpenter et al., 2006; Costanza et al., 1997; TEEB National and International Policy Making, 2011; TEEB Synthesis, 2010).

Around 1981, the concept of ecosystem services was introduced to indicate the societal value of nature and included ecosystem processes involved in an ecological system that may or may not be connected to humans. Over the years the field of valuing the benefits provided by ecosystem and biodiversity has evolved a lot. Right from 1987, when early attempts of valuing ecosystem services comprehensively by (De Groot, 1987), the field has evolved into a multi-stakeholder movement being carried out by various countries to understand and measure the value of their ecosystem and hence preserve it. One of the most comprehensive attempts to valuate ecosystem services was made by (Costanza et al. in 1997), who evaluated the economic value of entire ecosphere to be in the range between 16 - 54 trillion US\$ every year regardless of marketed and non-marketed service which in turn is considered as a minimum estimate due to uncertainties.

Further, in the early 2000s, due to the efforts made over the decades, the ecosystem services started getting reflected in the policy arena as well. The Ecosystem Approach as adopted by UNEP-CBD and the Global Biodiversity Assessment are just examples of these. As discussed in the introduction, the MEA framework was one of the most important stepping stones in this regard. After the MEA framework in 2007, the biggest landmark in assessing the value of ecosystem services, was the formulation of the TEEB project i.e. "The Economics of Ecosystem and Biodiversity" project. TEEB focuses on evaluating the hidden values of the ecosystem, cost of biodiversity loss and ecosystem degradation with the help of expertise from ecology, economics, and development to better equip the decision-makers for mainstreaming biodiversity and ecosystem considerations at all levels, including government and private. TEEB, in its first phase, released an interim report (TEEB interim report, 2008) setting up the path for a detailed assessment of biodiversity and ecosystem in economic terms with an ultimate aim of providing a tool to policymakers and decision-makers by helping them to incorporate the value of nature in their current decisions. TEEB followed 3 tier approach for the valuation: recognizing value (in the biodiversity and ecosystem); demonstrating value (in economic terms, to improve the visibility, causing defense mechanism) and capturing value (in decision making). There are different methods as reported by (Pascualthat and Muradianare, 2010) used to estimate economic values associated with ecosystem according to TEEB as follows

- Market price method: Based on the Commercial market, products and benefits of the ecosystem are monetized.

- Productivity method: Quantify the financial value of ecosystem-based on its service on traded goods.

- Hedonic pricing method: Quantify the economic value of service provided by ecosystem based on its direct effect on other marketed goods.

- Travel cost method: Estimates economic values of ecosystem based on the amount spent by people to travel the site.

- Damage cost avoided Replacement cost and Substitute costs method: Calculates economic value on the basis of amount saved by preventing the loss, renewal or substitution of the ecosystem.

- Contingent valuation method: Economic value is estimated by directly inquiring among the people about the willingness to spend or accept compensation on particular ecosystem services based on hypothetical conditions.

- Contingent choice method: Estimates economic values by asking people to market among the set of services in the ecosystem

- Benefit transfer method: Estimates the economic value of one location by transferring the study carried out at another location. 
The phase II of the TEEB, in 2010, lead to the publications in four key sectors, targeting varied audience. The reports were published under the heading: TEEB Ecological and Economic Foundations (explaining the fundamentals) (TEEB Ecological and Economic Foundations, 2010) TEEB in National and International Policy Making (targeted towards governments and their decision making) (TEEB National and International Policy Making, 2011); TEEB in Local and Regional Policy (targeted at local bodies like ULBs) (TEEB Local and Regional Policy Makers, 2010); TEEB in Business and Enterprise (targeted towards businesses and business leaders) (TEEB Business and Enterprise, 2012).

Over the years, TEEB has developed and has started country-specific studies, sector-specific TEEB Studies including, agriculture and food, Arctic, Fisheries and Ocean. In 2012, "TEEB for business coalition" came into existence through combined efforts of institutions globally. The aim/purpose of this coalition was to collect the detailed methodology and steps followed by some of the leading corporations and researchers to have in-depth mechanism that could be concluded for others or companies to follow for the valuation of their business externality. Later, the coalition was renamed as Natural Capital Coalition and led to the development of Natural Capital Protocol (NCP) which is detailed later in this report. In India also, TEEB had started in 2011 which led to the development of a report on Natural Capital of Wetlands of India in 2017 (Kumar et al., 2017).

In parallel to TEEB, the concept of Payment for Ecosystem Services (PES) also developed. PES, defined by UNDP, occurs when a payment is either directly or indirectly made to the service provider by the beneficiary. The concept is to conserve the ecosystem and it is so obtained service by paying for the same. ("An introductory guide to valuing ecosystem services," 2007) released a guide to valuing ecosystem services followed by a best practice guide (Smith et al., 2013). In India also, based on the United Nations' System of Economic and Environmental Accounting (SEEA)-2003 guidelines, Green Accounting for Indian States Project (GAISP) was undertaken to determine the value of ecosystem and biodiversity considering various ecosystems. The areas in which GAISP worked included the Value of timber, carbon, fuelwood, and non-timber forest products in India's forests estimating the value of agricultural cropland and pastureland. (Gundimeda et.al., 2007)found the ratio of environment adjusted state domestic product to adjusted net state domestic product greater than 1 for states like Tripura, Meghalaya, Kerala, Nagaland \& Tamil Nadu which indicated that the growth is sustainable and for those states whose ratio was below 1 were subjected to great stress on their forest ecosystem due to very state-specific factors. (Verma et al., 2017) estimated the benefits from 6 tiger reserves in India to be ranging from US\$769 ha-1 $\mathrm{Yr}^{-1}$ to US\$2923 ha-1 $\mathrm{yr}^{-1}$. The estimates arrived are not the price tags fro tiger, but are for the policy interventions to unaccounted positive externailites of tiger reserves. The concept of REDD+ (Reducing Emissions from Deforestation and Forest Degrdaradtion and the role of forest conservation, sustainable management of forests, and enhancement of forest carbon stocks in developing countries) is introduced in Indian context to ensure biodiversity conservation and flow of ecosystem services (TERI, nd; MOEF, 2018). Apart from these major frameworks of ecosystem services valuation, there are numerous case studies which have utilized and tweaked the already discussed frameworks and the science is still evolving. Figure 2 indicates the development of the field of ecosystems services measurement and valuation.

\section{ENVIRONMENTAL DAMAGE COST ASSESSMENT}

Another very important aspect of environmental economics is to assess the damage caused to the environment due to current business practices. This is important because of the current system of accounting links between the income and human well-being which is rather questionable since it does not reflect the equity in quality of life, ecological loading, informal or unorganized benefits and environmental degradation. In India, one of the early attempts of integrating the current accounting practices with the environmental parameters was done by CSIR-National Environmental Engineering Research Institute (CSIR-NEERI) aiming to quantify the extent of degradation in the resource as an awareness tool among the decision-makers prioritizing the importance of environment on socio-economic development towards minimizing environmental degradation and better quality of life. The study indicates that if environmental degradation is taken into account the net GDP is negative. (Khanna and Ram Babu, 1997) carried a study to integrate environment and economics account, which was found delineating due to several reasons such as poor air quality linked with damages in health and ecology, exploitation of groundwater resources, Loss of landmass due to erosion, waterlogging and excess alkalinity and breakdown of forest covers.

Globally, sensitization around the topic and the impact of current business practices and related climate change was known due to the Stern Review on the economics of climate change, which was released in 2006. The key points from the report (Stern, 2006) indicates the seriousness of irreparable impacts due to climate change concerning business practices. Further, the basic elements required for living like food, air, water, and health are threatened by climate change. In 2006, it was estimated that arresting the carbon dioxide concentration to $500-550 \mathrm{ppm}$ will require $1 \%$ of the global GDP whereas to arrest to $450 \mathrm{ppm}$, which is necessary for $2^{\circ} \mathrm{C}$, it may take up to 5 to $20 \%$ of the world's GDP. As per another paper (Tol and Yohe, 2006), stern has justified the cost of climate change (5-20\% of GDP) comparing the magnitude of the cost of carbon abatement ( $1 \%$ GDP) which led to a conclusion that benefits occurred from reducing emissions are minor compared to the cost of climate change.

As per the study carried out by (Nellamann et al., 2009) Considering the (Stern review, 2008) reported that Global change in climate may affect food production in several paths like bringing an overall change in growing conditions due to uneven rainfall and temperature, Due to severe calamities like flood, drought and storms and increasing extent of invasive infestations. There exist several studies in the field of ecosystem services that are unaddressed in countries like India due to lack of awareness.

There are many matrices available for the measurement of environmental damages. The environmental externalities, which are the third impacts of businesses, stem from air pollution, greenhouse gas emissions, water pollution, solid waste, land degradation freshwater consumption, land use/land cover drivers and biodiversity destruction. Each of these externalities can be measured using various approaches. Figure 3 shows the general approach in estimating the monetary damage to the environment 


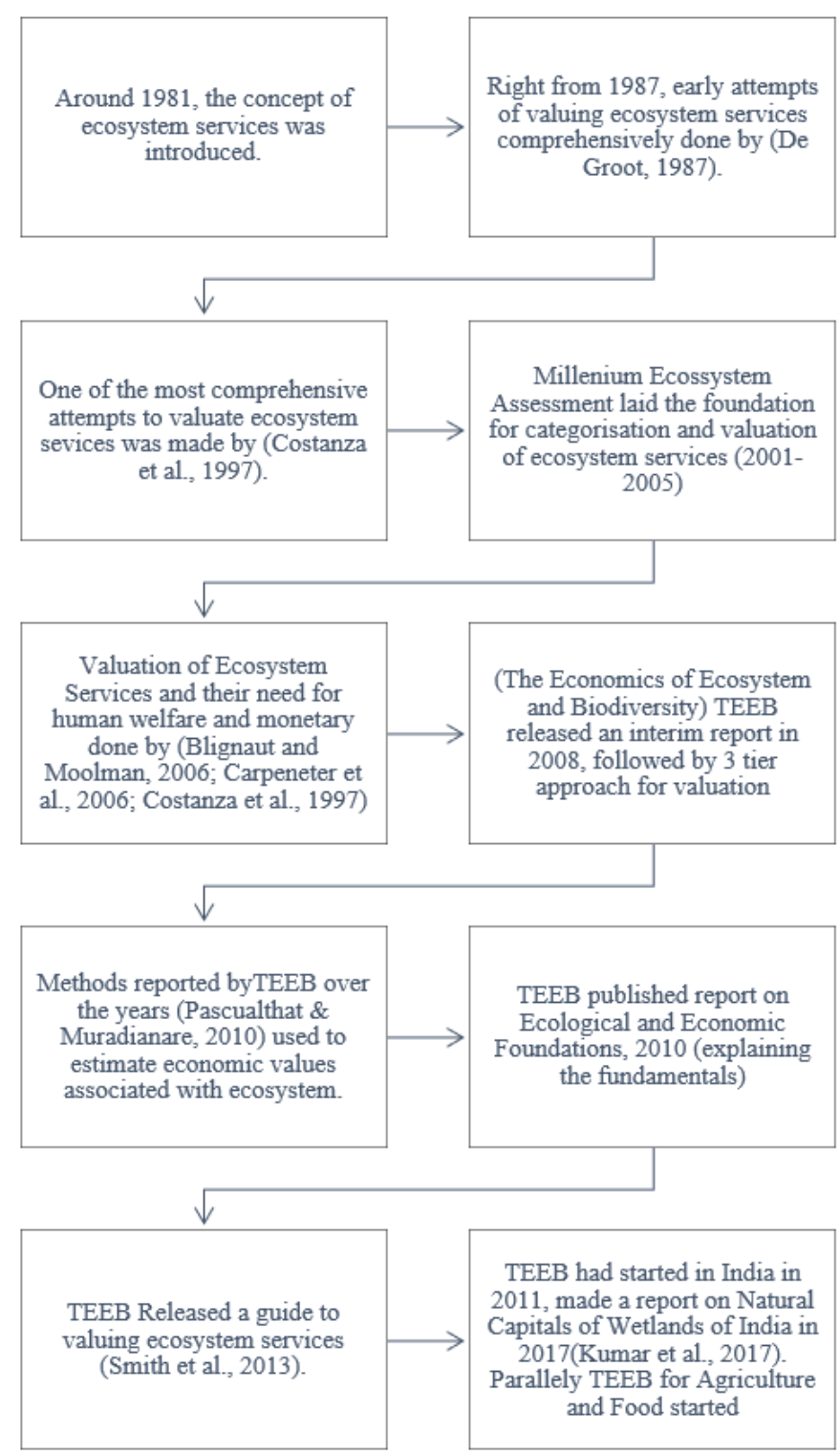

Figure 2. Major breakthroughs in the field of ecosystem services measurement and valuation

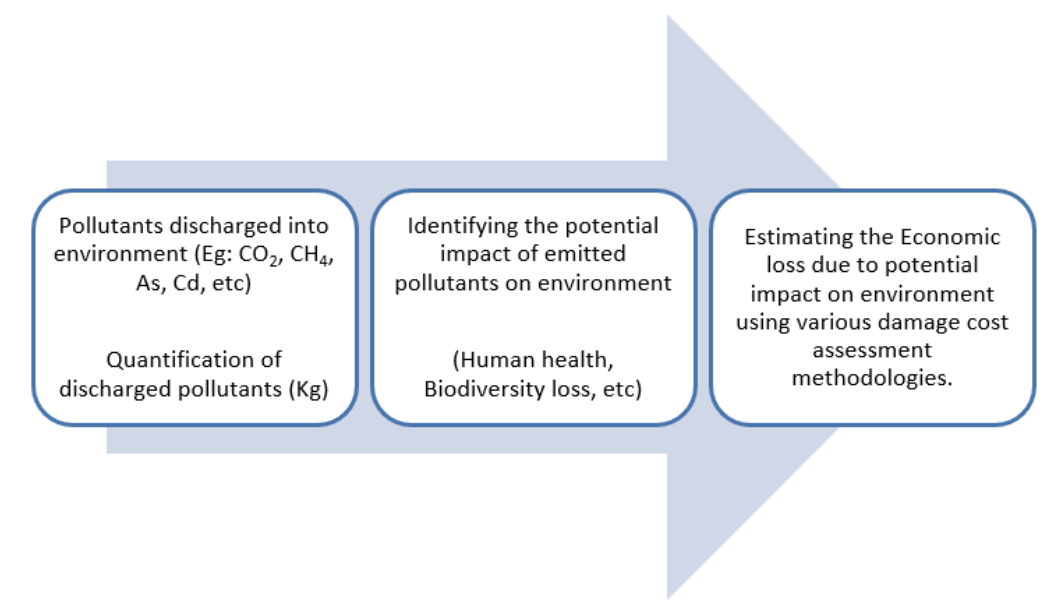

Figure 3. Generic principle followed in environmental damage cost assessment (Bherwani et al., 2019)

through negative externalities. Step 1: Identification and quantification of emitted pollutants that are likely to cause negative impacts on natural resources and human health. Step 2: Identification of adverse impacts/changes on natural resources and human health due to emitted pollutants. Step 3: Evaluation of monetary losses due to impact of emission on human wellbeing and natural environment. One of the early attempts to measure environmental externalities was by the ExternE project, which started in the 1990s' which was then continued till 2005. The ExternE stands for Externalities of Energy, in which the energy sector externalities were calculated using the Impact Pathway Methodology as mentioned in (ExternE - External Costs of Energy, n.d.). 
Table 2. Natural capital protocol approach

\begin{tabular}{ll}
\hline Stages & Action/ Approach plan \\
\hline Frame & Initialization of natural capital assessment \\
\hline Scope & Define scope, Objective \& impacts relevant to natural capital \\
\hline Measure \& Validate & Measure impact drivers, valuation of natural capital impact and change occurred in natural capital due to impact drivers. \\
\hline Apply & Interpret \& Validate the test and incorporate natural capital on the existing system. \\
\hline
\end{tabular}

One of the drivers of environmental degradation, greenhouse gases, has a potentially large and adverse effect on climate change. The policymakers on climate change have focused on the cost of mitigation and the net value of climate change in the coming years (Watkiss et al., 2005). The valuation of impacts associated with greenhouse gases is comprehensively estimated using the social cost of carbon (SCC). The SCC is the total estimate of damage due to climate change, the difference in agricultural yield, human health, damages due to natural calamities and energy-related cost. The SCC use cost-benefit analysis to compare the cost of emission reduction concerning cost of mitigation norms (EPA fact sheet, 2016). Specific tools are also available to conduct detailed analysis on a specific driver of externality. For example, if the valuation of water is to be carried out, a detailed methodology developed by International Finance Corporation (IFC) and World Wildlife Fund (WWF) can be used. The document titled "The Value of Water" gives a framework for understanding and conducting valuation of water (Morgan and Orr, 2015).

Companies, realizing their sustainability depends on understanding the true value of nature and how much harm they are creating was the reason for initiating environmental externalities calculations. Puma was one of the first few companies to produce their environmental profit and loss in 2011 with the help of Trucost and PwC. Puma revealed an ecological footprint of $£ 124$ million (Guest, 2011). Kering Group, the parent company of Puma, has since evolved its methodology to a much finer extent. Trucost, on the other hand, did a calculation for the top 100 environmental externalities globally, which formed the basis of their company. The study was commissioned by TEEB.

Further, to consolidate and standardize approach in the valuation of externalities, the Natural Capital Protocol (NCP) was created. The NCP, developed by NCC and launched in 2016, applies to any business sector, operating in any geography, at any organizational level. It allows you to measure, value and integrate natural capital into your existing business processes. Table 2 gives an overall view into its NCP's approach ("Natural capital protocol," n.d).

In India there have been various studies related to environmental externalities, for example, NEERI (Environmental Impact Assessment (EIA) Study on Pollution Due to Oil Spill and Other Hazardous Substances, 2011) carried study on oil spill damages due to collision of MSC Chitra and MV Khalijia on 7th August 2010. The study estimated damage of around 358 million dollars. If cleanup was to be carried out, the damage cost was around 351 million dollars with the cost of clean-up. In 2013, positive externalities of livestock farming were estimated but not monetized (Dikshit and Birthal, 2013). In 2013, a World Bank document was released, scoping physical and monetary losses of environmental health natural resources (World Bank, 2013). Bherwani et al. (2019) published a recent report elaborating the methodology for valuating damages on-air environment, water environment, climate change and solid waste due to the emission of breached concentration of pollutants. The report has used various methodologies such as the Value of statistical life, cost of illness, willingness to pay, direct benefit transfer, the social cost of carbon, etc to evaluate the potential damage cost of the environment. Figure $\mathbf{4}$ gives a gist of stepping stones of the environmental damages evaluation field.

\section{VALUATION AS A MANAGEMENT TOOL}

Larger research in the field of ecosystem services are by developed countries (Xie et al., 2020). It is important to emphasize the valuation approaches in other parts of the world too either by seeking assistance from developed countries or being self reliant utilising available resources/research materials so as to maintain the sustainability of their thriving ecosystem. The economic growth of the world started majorly with industrialization and the same is true for India, which saw its growth in industries soon after its independence (Singh, 2016). The raw material required for different industries directly or indirectly comes from the natural resources, the ecosystem and the biodiversity. The problem is not the utilization of the natural resources but the indiscriminate and overexploitation of ecosystem or unsustainable use of the very biodiversity that has life-sustaining functions. Often businesses and communities forget that they are part of the ecosystem, such that if the environment is polluted or degraded ultimately humans are going to get affected adversely (Appannagiri, 2017). Biodiversity loss threatens human economic activity by destroying the resources millions of people rely upon for their own lives and livelihoods. Hence it is our responsibility to maintain and preserve the structure of our current habitats and ecosystems as well as the economic systems and industries which they support.

Today's for profit-oriented businesses and communities need to understand that if they do not value the environment, ecosystem, and biodiversity properly, in time they are going to cost them dearly. So much so that companies had and will have to shut down operations because of the non-availability of natural resources in a particular region. But, to make businesses, governments, communities, and the public in general, understand the true value of nature, it is necessary to demonstrate it and hence the valuation is necessary (Pascual et al., 2017).

Further, the process of valuation is an excellent tool for policymakers, helping them decide the priorities and action steps leading to environmental preservation. In India, the importance of preserving the environment is increasing rapidly. The valuations can be used for deciding the cost and benefit of a particular project keeping the environment as the central parameter. For example, if a project of highways is coming up, apart from the regular environmental impact assessment, the valuation 


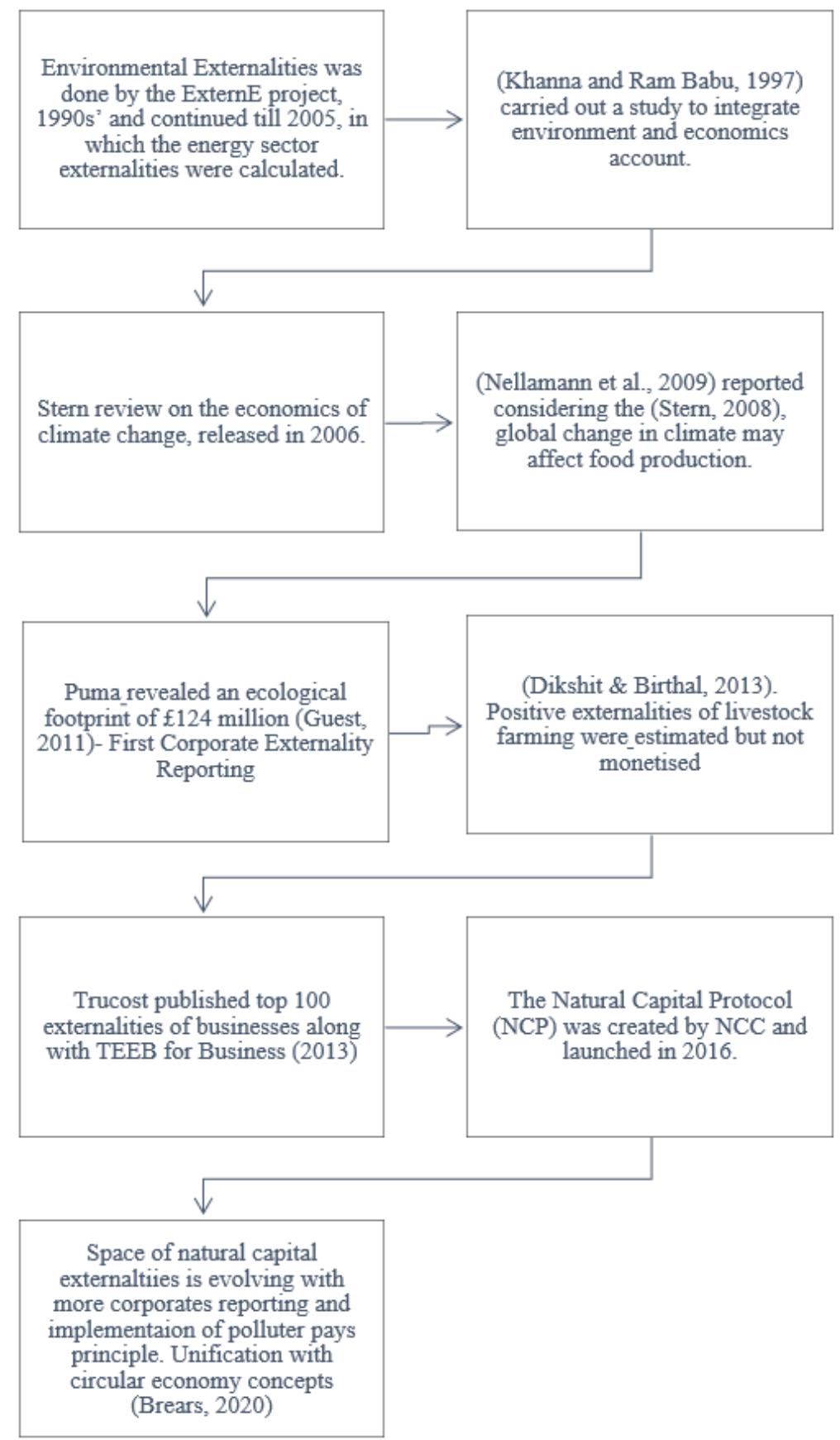

Figure 4. Major breakthroughs in the field of Environmental Externalities Evaluation

concerning externalities and effect on ecosystem services can be calculated and can be compared with the benefits of the project. This may help in identifying the most important parameters which are to be preserved in the interest of the environment. Another important example where valuations can be handy is of the 2016 Central Pollution Control Board, India guidelines on implementing liabilities for environmental damages due to the handling and disposal of hazardous wastes. The guidelines suggest that penalties are to be imposed depending upon the level of hazard which has taken place and if the company itself is taking action or Central Pollution Control board (CPCB) or State Pollution control Board (SPCB) has to intervene first. However, the process of deciding penalties is not decided based on a particular externalities evaluation methodology, which is the need of the hour. Similarly, on violation cases in the realty sector, the guidelines are being formulated for penalizing the businesses who have not obtained the environmental clearances beforehand. In such a case, a tool can be developed based on the above methodologies to assess the actual damage to the environment and hence determine the value of penalty. The above example applies to many other countries as well and not just India. There are few countries like Sweden, UK and United States have adopted the Polluter Pays Principle to a limited extent. However, when it comes to widespread application, in all the policy matters where environment is one of the key factors, it still needs to be seen how it can be achieved.

Furthermore, there is need to develop country-specific database for the data and methodologies used for valuation so that unambiguous policy decisions can be taken which will be based on the methodology and database adopted by the respective country. Finanical support is also an underlying truth required to support developing countries to implement the suggested measures for sustianble development. Having said that, it is important that the developed literature is already used wherever 
possible so that the framework remains similar. There are many cases like above which are pointing a need to do a detailed valuation exercise as per the need of the country. The above cases indicate a need to develop a strong database at a country level and start holistically valuing nature to make our current growth sustainable.

\section{DISCUSSION}

The paper explicitly demonstrates that environmental and developmental economists who used to ignore each other in the past are collaborating on research, realizing the fact that environmental quality is an important input to economic growth that cannot be overlooked. the world we live in is changing rapidly. One of the most important components of our world is the environment in which we humans and bio-diversity thrive upon. Pressing human activities, fueled by increasing demand, are detrimental to our environment. To manage and preserve the ecosystem services and reduce the environmental impacts due to pollution, measurement of these impacts is very important. Change in ecosystem service can change the benefits associated with human welfare. Ecosystem services valuation is evolving as an important tool to measure and manage the services in a better and innovative manner. However, regional specificity must be brought into frameworks when a particular niche is being evaluated.

A related subject to ecosystem services is environmental damages. Environmental damages over the years are leading to a negative impact on biodiversity and human beings. As a result, the laws related to pollution are becoming stricter and stricter, in turn affecting the businesses. Businesses and industries are dependent on nature for the supply of resources; be it water, air, metals, fuel, etc. Our growing population and demand-supply gap are putting pressure on the businesses and industries to perform better and better every day. Moreover, the stock of raw materials is decreasing. The business as usual scenario disregards the fact that our environment has a finite assimilative capacity for pollutants. Once the limit is breached, all kinds of problems including, but not limited to, the decline in human health, extinction of species, losses of aquatic systems, climate change and so on will stand in our face with limited solutions at our bay. It becomes important to preserve the environment and thus society at large by assessing the assimilative and carrying capacity of the environment and finding better and green solutions to curb pollution.

The industries and businesses are polluting on a scale which is breaching the set standards. It is becoming essential that we should have a mechanism of accounting for the damages being done to the environment. The necessity to develop a framework that can apply the laws and regulations like "polluter pays principle" and "extended producers responsibility" has become very relevant in today's environment. To implement the above principles, regulators are looking forward to a systematic framework that can guide them to evaluate the damages to the environment, to recover the cost of restoration and bring in application of constructive ideas for the betterment of the environment. Degradation of nature has reached a critical level where environmental damage cost might accelerate at a vigorous pace if business at the same pace is continued. The value of damages can be recovered from the polluter and can be used constructive activities for the betterment of the environment. Moreover, it is clear that how businesses operate in the future will need to be transformed. Expectations of governments, societies, customers, and suppliers are already changing. There is a growing recognition that the good/right kind of growth is also possible and that businesses need to consider stakeholders into perspective beyond the old school shareholder perspective. The country-specific framework also helps businesses to understand the impact of their actions and help them channelize their energy into doing inclusive growth. If proper measurement of damages in monetary terms is calculated, corresponding penalties can be levied on the businesses, in turn helping businesses change for the betterment of the environment. Here also, it is important to create region-specific frameworks for damage cost assessment along with the use of region-specific data to arrive at robust methodology and numbers to address the problem on the ground effectively to make governments, industries, businesses, societies and people in general, understand the magnitude of impact generated by breach of environmental standards.

Summing up, the critical aspects to be developed in near future for the advancement of above field are given in Figure 5.

Various critical aspects depicted in Figure 5 are described below:

1. Valuation of ecosystem services can prove to be a handy tool. Specific valuations exercises of niche ecosystems like Mangroves, Lakes, Agricultural and Food Systems etc should be carried out at regional level so that they can be incorporated with decision making for development.

2. Conventional environmental assessments methods like Carrying Capacity Assessment (CCA) and Environmental Impact Assessment (EIA) should be advanced to include ecosystem services and environmental damages accountability to make a better and informed decision.

3. Life Cycle Assessment (LCA) is another conventional method which assess the environmental impacts at midpoint level (for example concentration of pollutants released in air). The technique should be upgraded to include endpoint analysis i.e. include externalities evaluation in monetary terms into the methodology to bring forth the overall impact in a terminology understandable by experts from wide-ranging fields.

4. Frameworks of environmental externalities should also be developed at regional scale for exhaustive and wide-spread implementation of polluter pays principle

5. The use of valuation of ecosystem services and environmental externalities cannot be and should not be restricted just to policymakers. Businesses need to understand that business as usual scenario will not work in near future and the above frameworks are needed to be embedded in their core working policy. The tailoring of above frameworks for the businesses is becoming need of the hour. 


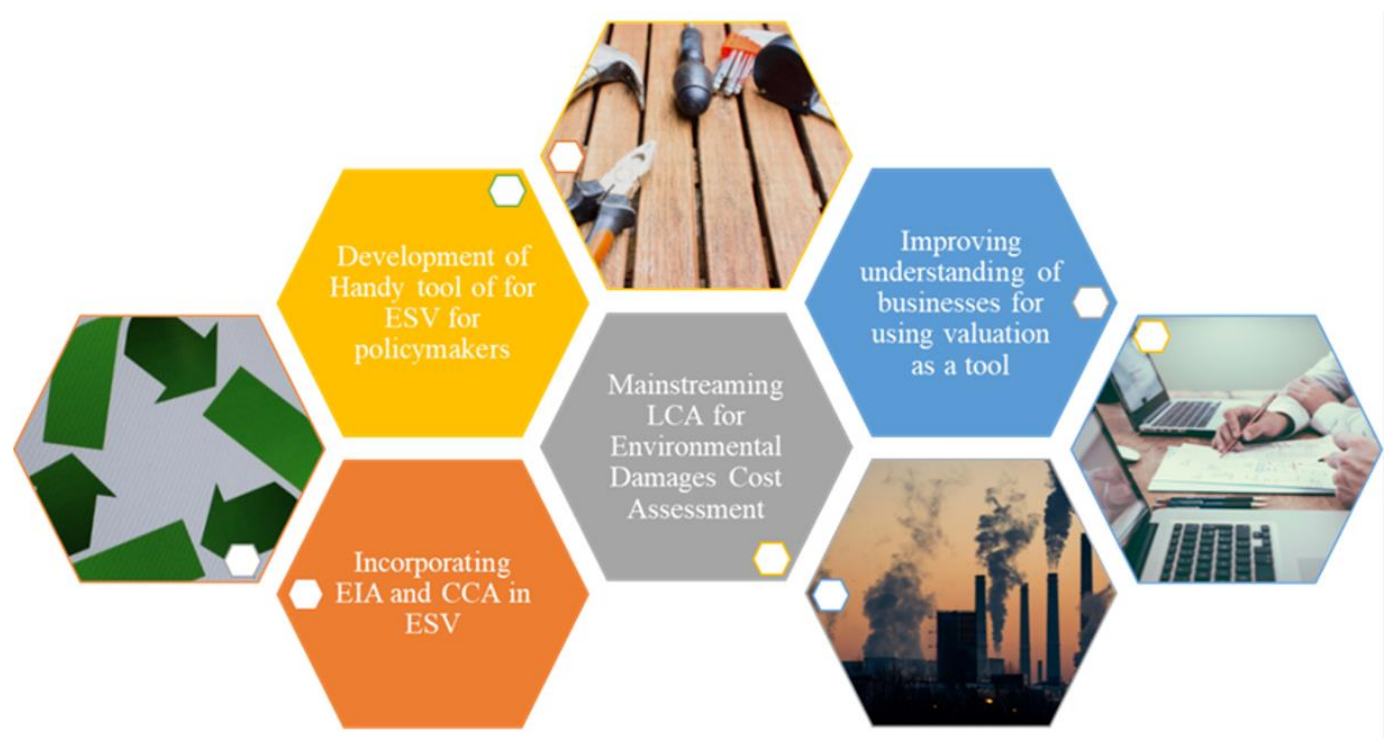

Figure 5. Critical Areas of Intervention for Future Development of the field

It is important that the literature which has been developed over the years in this field be utilized effectively for environmental conservation. Moreover, the above points along with recommended frameworks and their similarities, can be used as an effective tool for policymaking for a better environment and for a sustainable world including businesses and industries.

\section{REFERENCES}

Agudelo, M. A. L., Johannsdottir, L. and Davidsdottir, B. (2019). A literature review of the history and evolution of corporate social responsibility. International Journal of Corporate Social Responsibility, 4, 1-23. https://doi.org/10.1186/s40991-018-0039-y

Alcamo, J., Ash, N. J., Butler, C. D., Callicot, J. B., Capistrano, D., Carpenter, S. R., ... Zurek, M. B. (2003). Ecosystems and Human Well-being: A Framework for Assessment. Millennium Ecosystem Assessment. Retrieved from https://www.millenniumassessment.org/documents/document.356.aspx.pdf

An introductory guide to valuing ecosystem services. (2007). Retrieved from http://ec.europa.eu/environment/nature/ biodiversity/economics/pdf/valuing_ecosystems.pdf

Appannagari, R. R. (2017). Environmental Pollution Causes and Consequences: A Study. North Asian International Research Journal of Social Science \& Humanities, 3, 151-161.

Aye, C. J. and Edoja, P. E. (2017). Effect of economic growth on CO2 emission in developing countries: Evidence from a dynamic panel threshold model. General \& Applied Economics, 5, 1-22. https://doi.org/10.1080/23322039.2017.1379239

Balmford, A., Rodrigues, A. S. L., Walpole, M., ten Brink, P., Kettunen, M., Braat, L. and de Groot, R. (2008). The Economics of Ecosystems and Biodiversity: Scoping the Science. Cambridge, UK: European Commission.

Baveye, P. C., Jacques, B. and John, G. (2016). Soil "Ecosystem" Services and Natural Capital: Critical Appraisal of Research on Uncertain Ground. Frontiers in Environmental Science, 4, 41. https://doi.org/10.3389/fenvs.2016.00041

Bherwani, H., Gupta, A., Nair, M., Sonwani, H. and Kumar, R. (2019). Framework for environmental damages cost assessment with examples. Special report on monetizing damages. CSIR-National Environmental Engineering Research Institute.

Blignaut, J. and Moolman, C. (2006). Quantifying the potential of restored natural capital to alleviate poverty and help conserve nature: a case study from South Africa. Journal for Nature Conservation, 14, 237-248. https://doi.org/10.1016/j.jnc.2006.04.001

Brears, R. C. (2020). The Circular Water Economy. In: Developing the Circular Water Economy. Palgrave Studies in Climate Resilient Societies. Palgrave Pivot, Cham. https://doi.org/10.1007/978-3-030-32575-6

Brockerhoff, E. G., Barbaro, L., Castagneyrol, B., et al. (2017). Forest biodiversity, ecosystem functioning and the provision of ecosystem services. Biodiversity and Conservation, 26, 3005-3035. https://doi.org/10.1007/s10531-017-1453-2

Carpenter, S. R., DeFries, R., Dietz, T., Mooney, H. A., Polasky, S., Reid, W. V. and Scholes, R. J. (2006). Millennium ecosystem assessment: research needs. Science, 314, 257-258. https://doi.org/10.1126/science.1131946

Cohen, A. J., Brauer, M., Burnett, R., Anderson, H. R., Frostad, J., Estep, K., et al. (2017). Estimates and 25-year trends of the global burden of disease attributable to ambient air pollution: an analysis of data from the Global Burden of Diseases Study. Lancet, 389, 1907-1918. https://doi.org/10.1016/S0140-6736(17)30505-6

Crossman, N. D., Bryan, B. A. (2009). Identifying cost-effective hotspots for restoring natural capital and enhancing landscape multi-functionality. Ecological Economics, 68, 654-668. https://doi.org/10.1016/j.ecolecon.2008.05.003

Crossman, N. D., Bryan, B. A. and Summers, D. M. (2011). Carbon payments and low-cost conservation. Conservation Biology, 25, 835-845. https://doi.org/10.1111/j.1523-1739.2011.01649.x 
D’Amato, D., Rekola, M., Li, N. and Toppinen, A. (2016). Monetary valuation of forest ecosystem services in China: a literature review and identification of future research needs. Ecol Econ, 121, 75-84. https://doi.org/10.1016/j.ecolecon.2015.11.009

De Groot, R. S. (1987). Environmental functions as a unifying concept for ecology and economics. The Environmentalist, 7(2), 105109. https://doi.org/10.1007/BF02240292

De Groot, R., Perk, V. D. P. J., Chiesura, A. and Vliet, V. A. (2003). Importance and threat as determining factors for criticality of natural capital. Ecological Economics, 44, 187-204. https://doi.org/10.1016/S0921-8009(02)00273-2

Dikshit, A. K. and Birthal, P. S. (2013). Positive Environmental Externalities of Livestock in Mixed Farming Systems of India. Agricultural Economics Research Review, 26(1), 21-30. https://doi.org/10.22004/ag.econ.152069

Environmental Impact Assessment (EIA). (2011). Study on Pollution Due to Oil Spill and Other Hazardous Substances. National environmental engineering research institute. Retrieved from http://mpcb.gov.in/images/pdf/OilSpillinterimreport-NEERI.pdf

EPA fact sheet. (2016). Retrieved from https://www.epa.gov/sites/production/files/2016-12/documents/social_cost_of_ carbon_fact_sheet.pdf

European Commission. (2000). A Study on the Economic Valuation of Environmental Externalities from Landfill Disposal and Incineration of Waste. Retrieved from https://ec.europa.eu/environment/enveco/waste/pdf/cowi_ext_from_landfill.pdf

ExternE - External Costs of Energy. (n.d). Retrieved from http://www.externe.info/externe_d7/?q=node/46

Gillies, G. I. (2010). The current economic crisis and international business. Can we say anything meaningful about future scenarios? Futures, 42, 910-919. https://doi.org/10.1016/j.futures.2010.08.018

Graf, J. Z. and Neidell, M. (2012). The impact of pollution on worker productivity Am. Econ. Rev., 102, 3652-3673. https://doi.org/10.1257/aer.102.7.3652

Guest, P. (2011). Puma Reveals Its $£ 124 m$ Ecological Footprint in Groundbreaking New Research. Retrieved from https://www.huffingtonpost.co.uk

Gundimeda, H., Sukhdev, P., Sinha, R. K. and Sanyal, S. (2007). Natural resource accounting for Indian states - Illustrating the case of forest resources. Ecological Economics, 61(4), 635-649. https://doi.org/10.1016/j.ecolecon.2006.07.035

Hanna, R. and Oliva, P. (2015). The effect of pollution on labor supply: evidence from a natural experiment in Mexico City. J. Public Econ., 122, 68-79. https://doi.org/10.1016/j.jpubeco.2014.10.004

Kelsey, B. J. (2017). Environmental economics in developing countries: An introduction to the special issue. Journal of Environmental Economics and Management, 86, 1-7. https://doi.org/10.1016/j.jeem.2017.08.007

Khanna, P. and Ram Babu, P. (1997). Environmental Evaluation of Economic Growth: An Agenda for Change, Yojana.

Kumar, R., Bhatt, J. R. and Goel, S. (2017). Natural Capital of Wetlands. New Delhi. Wetlands International South Asia, 45.

Lele, S. and Srinivasan, V. (2013). Disaggregated economic impact analysis incorporating ecological and social trade-offs and techno-institutional context: a case from the Western Ghats of India. Ecological Economics, 91, 98-112. https://doi.org/10.1016/j.ecolecon.2013.03.023

Lorek, S. and Spangenberg, J. H. (2014). Sustainable consumption within a sustainable economy - beyond green growth and green economies. Journal of Cleaner Production, 63, 33-44. https://doi.org/10.1016/j.jclepro.2013.08.045

MEA. (2005). Ecosystem and human wellbeing synthesis. Retrieved from https://www.millenniumassessment.org/documents/document.356.aspx.pdf

Mengist, W. and Soromessa, T. (2019). Assessment of forest ecosystem service research trends and methodological approaches at global level: a meta-analysis. Environ Syst Res, 8, 22. https://doi.org/10.1186/s40068-019-0150-4

MOEF (2018). National REDD+strategy INDIA. Retrieved from https://redd.unfccc.int/files/india_national_redd__strategy.pdf

Morgan, A. J. and Orr, S. (2015). The value of water: A framework for understanding water valuation, risk and stewardship (Discussion draft). Retrieved from https://d2ouvy59p0dg6k.cloudfront.net/downloads/the_value_of_water_discussion_ draft_final_august_2015.pdf

Mori, K. and Christodoulou, A. (2012). Review of sustainability indices and indicators: Towards a new City Sustainability Index (CSI). Environmental Impact Assessment, 32, 94-106. https://doi.org/10.1016/j.eiar.2011.06.001

Natural capital protocol. (n.d). Retrieved from http://naturalcapitalcoalition.org/wp-content/uploads/2016/07/NCC_Primer_ WEB_2016-07-08.pdf

Nellemann, C., MacDevette, M., Manders, T., Eickhout, B., Svihus, B., Prins, A. G. and Kaltenborn, B. P. (2009). The environmental food crisis - The environment's role in averting future food crises. Retrieved from https://www.gwp.org/globalassets/ global/toolbox/references/the-environmental-crisis.-the-environments-role-in-averting-future-food-crises-unep-2009.pdf

Pascual, U. and Muradian, R. (2010). The economics of valuing ecosystem services and biodiversity. Retrieved from http://doc.teebweb.org/wp-content/uploads/2013/04/D0-Chapter-5-The-economics-of-valuing-ecosystem-services-andbiodiversity.pdf

Pascual, U., Balvanera, P., Díaz, S., Pataki, G., et al. (2017). Valuing nature's contributions to people: the IPBES approach. Current Opinion in Environmental Sustainability, 26, 7-16. https://doi.org/10.1016/j.cosust.2016.12.006

Pearce, D. (2002). An Intellectual History of Environmental Economics. Annual Rev. Energy Environ, $27,57-81$. https://doi.org/10.1146/annurev.energy.27.122001.083429 
Pece, A. M, Simona, O. E. O. and Salisteanu, F. (2015). Innovation and Economic Growth: An Empirical Analysis for CEE Countries. Procedia Economica and Finance, 26, 461-467. https://doi.org/10.1016/S2212-5671(15)00874-6

Pollution costs India \$80 billion a year: World Bank. (2017). Retrieved from https://www.ndtv.com/world-news/pollution-costsindia-80-billion-a-year-world-bank-528678

Roe, D. (2019). Biodiversity loss- More than an environmental emergency. The Lancet Plantary health, 3(7), $287-289$. https://doi.org/10.1016/S2542-5196(19)30113-5

Ropke, I. (2004). The early history of modern ecological economics. Ecological Economics, 50, $293-314$. https://doi.org/10.1016/j.ecolecon.2004.02.012

Sánchez, J. A. A., Muñoz, J. F. V., Ureña, L. J. B. and Agugliaro, F. M. (2019). The worldwide research trends on water ecosystem services, Ecological Indicators, 99, 310-323. https://doi.org/10.1016/j.ecolind.2018.12.045

Sancho, F. H., Senante, M. M. and Garrido, R. S. (2010). Economic valuation of environmental benefits from wastewater treatment processes: An empirical approach for Spain. Science of total environment, 408(4), 953-957. https://doi.org/10.1016/j.scitotenv.2009.10.028

Sandmo, A. (2015). The Early History of Environmental Economics. Review of Environmental Economics and Policy, 9(1), 43-63. https://doi.org/10.1093/reep/reu018

Schirpke, U., Tappeiner, U. and Tasser, E. (2019). A transnational perspective of global and regional ecosystem service flows from and to mountain regions. Sci Rep, 9, 6678. https://doi.org/10.1038/s41598-019-43229-z

Singh, R. (2016). Disinvestment of Indian Public Sector Enterprises: A Global Prespective. BEST: International Journal of Management, Information Technology and Engineering, 4, 81-94.

Small, N., Munday, M. and Durance, I. (2017). The challenge of valuing ecosystem services that have no material benefits. Global Environmental Change, 44, 57-67. https://doi.org/10.1016/j.gloenvcha.2017.03.005

Smith, S., Rowcroft, P., Everard, M., Couldrick, L., Reed, M., Rogers, H., et al. (2013). Payments for Ecosystem Services: A Best Practice Guide. London: Defra.

Stern, N. (2006). Stern Review on economics of climate change. Retrieved from http://mudancasclimaticas.cptec.inpe.br/ rmclima/pdfs/destaques/sternreview_report_complete.pdf

TEEB Business and Enterprise. (2012). Edited by J. Bishop. London and New York: Earthscan. Retrieved from http://www.teebweb.org/media/2012/01/TEEB-For-Business.pdf

TEEB Ecological and Economic Foundations. (2010). Edited by P. Kumar. London and Washington: Earthscan. Retrieved from http://www.teebweb.org/wp-content/uploads/Study\%20and\%20Reports/Reports/Ecological\%20and\%20Economic\%20 Foundations/TEEB\%20Ecological\%20and\%20Economic\%20Foundations\%20report/TEEB\%20Foundations.pdf

TEEB interim report. (2008). Retrieved from http://www.teebweb.org/media/2008/05/TEEB-Interim-Report_English.pdf

TEEB Local and Regional Policy Makers. (2010). Retrieved from http://www.teebweb.org/media/2010/09/TEEB_D2_Local_PolicyMakers_Report-Eng.pdf

TEEB National and International Policy Making. (2011). Edited by P. ten Brink. London and Washington: Earthscan. Retrieved from http://www.teebweb.org/wp-content/uploads/2017/03/TEEB-for-Policy-Makers_Website.pdf

TEEB Synthesis. (2010). Mainstreaming the Economics of Nature: A Synthesis of the Approach Conclusions and Recommendations of TEEB. London and Washington: Earthscan. Retrieved from http://www.teebweb.org/wp-content/uploads/Study\%20and \%20Reports/Reports/Synthesis\%20report/TEEB\%20Synthesis\%20Report\%202010.pdf

TERI. (n.d). Conservation of biodiversity and ecosystem services by REDD+ project in India - Policy brief. Retrieved from https://www.teriin.org/projects/nfa/2008-2013/pdf/Policy_Brief_Conservation_biodiversity.pdf

The Gazette of India. (2017). Retrieved from http://envfor.nic.in/sites/default/files/S.O.804(E)\%20\%20Violation\%20of\%20EC $\% 20$ Cases.Pdf

Tol, R. S. J. and Yohe, G. W. (2006). Of Dangerous Climate Change and Dangerous Emission Reduction. Avoiding Dangerous Climate Change, Cambridge University Press, Cambridge, Chapter 30, 291-298.

Verma, M., Negandhi, D., Khanna, C., Edgaonkar, A., David, A., Kadekodi, G. ... Kumar, S. (2017). Making the hidden visible: Economic valuation of tiger reserves in India. Ecosystem Services, 26, 236-244. https://doi.org/10.1016/j.ecoser.2017.05.006

Watkiss, P., Anthoff, D., Downing, T., Hepburn, C., Hope, C., Hunt, A. and Tol, R. (2005). The Social Costs of Carbon (SCC) Review Methodological Approaches for Using SCC Estimates in Policy Assessment. Department for Environment, Food and Rural Affairs.

Winn, M, I. and Pogutz, S. (2013). Business, Ecosystems, and Biodiversity: New Horizons for Management Research. Organization \& Environment, 26, 203-229. https://doi.org/10.1177/1086026613490173

World Bank. (2013). India Diagnostic Assessment of Select Environmental Challenges An Analysis of Physical and Monetary Losses of Environmental Health and Natural Resources. Retrieved http://documents.worldbank.org/curated/en/220721468268504319/pdf/700040v10ESWOP0box0374379B00PUBLIC0.pdf

Xie, H., Zhang, Y., Choi, Y. and Li, F. (2020). A Scientometrics Review on Land Ecosystem Service Research. Sustainability, $12,2959$. https://doi.org/10.3390/su12072959 